\title{
Is it better on top? The triumph of supra-annular valves
}

\author{
S. Khan, MD \\ A. Trento, MD
}

\footnotetext{
From the Division of Cardiothoracic Surgery, Cedars-Sinai Medical Center, Los Angeles, Calif.

Received for publication May 3, 2001; accepted for publication May 17, 2001.

Address for reprints: Steven Khan, MD, Division of Cardiothoracic Surgery, Cedars-Sinai Medical Center, 8700 Beverly Blvd, Room 6215, Los Angeles, CA 90048.

J Thorac Cardiovasc Surg 2003;125:S12-3

Originally published in $\mathrm{J}$ Thorac Cardiovasc Surg 2001;122:645-6.

Copyright (C) 2003 by The American Association for Thoracic Surgery

$0022-5223 / 2003 \$ 30.00+0$

doi: $10.1067 / \mathrm{mtc} .2003 .210$
}

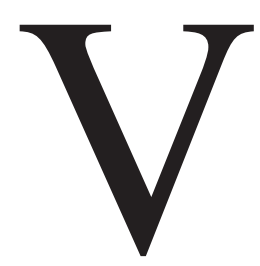

alve selection in the patient with a small aortic root remains a difficult decision for cardiac surgeons. Use of smaller stented porcine tissue valves in these patients may result in high gradients and low effective orifice areas. ${ }^{1,2}$ In some cases, there may be prosthesis-patient mismatch, ${ }^{3}$ which can result in persistent left ventricular hypertrophy after valve replacement and has been reported in up to $52 \%$ of patients. ${ }^{4}$ Jin and colleagues 5 found no significant regression of left ventricular hypertrophy in patients after implantation of either stented tissue valves or mechanical valves, although patients receiving unstented tissue valves and homografts did demonstrate significant regression.

Recognition of the potential importance of prosthesis-patient mismatch has led to interest in developing valve substitutes with improved hemodynamics. Although much of the recent literature has focused on stentless tissue valves, more traditional valve designs have also evolved to meet this challenge. The St Jude Medical HP (High Performance) valve was designed to allow supra-annular placement of the valve through modification of the sewing ring on a standard St Jude Medical valve. This allows a valve approximately one size larger to be inserted in the same size aortic root. Intuitively, one would expect this valve to have lower pressure gradients possibly resulting in better remodeling of the ventricle and more complete regression of hypertrophy after valve replacement than the standard cuff (SC) St Jude Medical valve. However, evidence for an improvement in hemodynamics with the HP valve has been lacking.

In this issue of the Journal, Vitale and coworkers ${ }^{6}$ report a randomized, multicenter trial comparing the postoperative and 6-month hemodynamics between the St Jude Medical HP and SC valves. The results are interesting on several levels. When HP and SC valves were compared at 6 months, both peak and mean pressure gradients were lower in the 21-mm and 23-mm HP valves than in the SC valves of the same size. However, effective orifice area did not differ significantly between $\mathrm{SC}$ and HP valves. A possible explanation for this finding lies in the greater cardiac output in the patients with SC valves in this series, which makes it difficult to draw definitive conclusions about the hemodynamic superiority of HP over SC valves. At 6 months, both the 21-mm and 23-mm HP valves demonstrated similarly low gradients (mean gradients of 18.8 and $14.9 \mathrm{~mm} \mathrm{Hg}$, respectively) and good effective orifice areas $\left(1.56 \mathrm{~cm}^{2}\right.$ and $1.60 \mathrm{~cm}^{2}$, respectively). These observations suggest that aortic root enlargement procedures may not be needed to upgrade from a 21-mm HP valve to a $23-\mathrm{mm}$ HP valve since little additional hemodynamic benefit accrues. Vitale and coworkers also examined the prevalence of postoperative patient-prosthesis mismatch. In contrast to the high prevalence in prior reports noted above, no patient in this series had patient-prosthesis mismatch according to an effective area index less than $0.9 \mathrm{~cm}^{2} / \mathrm{m}^{2}$, slightly stricter criteria than recommended by Pibarot and Dumesnil. ${ }^{4}$

Interestingly, $\mathrm{HP}$ valves showed a progressive reduction in gradient and effective orifice area in serial measurements after implantation. Since the HP valve is mechanical and fixed in size, no changes in shape or geometry of the valve itself are possible. This suggests that there may be remodeling either of the outflow tract or of the distal aorta allowing a closer matching of valve size with either outflow tract or aortic size. This late reduction in gradient has been reported in several previous studies with stentless valves. ${ }^{7,8}$ Vitale's article demonstrates that this late reduction 
in gradient can occur in St Jude Medical HP valves and therefore suggests that the underlying process, whether aortic root remodeling or left ventricular outflow tract remodeling, can also occur with bileaflet mechanical valves.

The present study leaves open several questions for future investigation. The most important clinical sequela of elevated aortic valve gradients after valve replacement is incomplete regression left ventricular hypertrophy. De Paulis and colleagues ${ }^{9}$ have shown that although regression of left ventricular hypertrophy does occur with bileaflet valves, it may be incomplete and result in persistent elevations in left ventricular mass, primarily as a result of residual septal thickening. The degree of septal thickness has also been shown to be an independent predictor of mortality in patients with aortic stenosis. ${ }^{10}$ It would be of great interest to see comparative data on changes in left ventricular mass and septal thickness in the present study and to determine whether left ventricular mass was more likely to return to normal in the HP group.

In summary, these findings suggest that the 21-mm and 23-mm St Jude Medical HP bileaflet mechanical valves are a reasonable choice in the patient with a small aortic root and did not result in patient-prosthesis mismatch. Ideally, the ultimate goal of the newer, more hemodynamically efficient valve designs should be to allow complete regression of hypertrophy. Further studies are still required to determine the long-term effects of both stentless and supraannular mechanical valves on left ventricular mass, as well as interactions with patient factors such as genetics ${ }^{11}$ and systemic blood pressure.

\section{References}

1. Cohn LH, Sanders JH, Collins JJ. Aortic valve replacement with the Hancock porcine xenograft. Ann Thorac Surg. 1976;22:221-7.

2. Jones EL, Craver JM, Morris DC, King SB 3rd, Douglas JS Jr, Franch $\mathrm{RH}$, et al. Hemodynamic and clinical evaluation of the Hancock xenograft bioprosthesis for aortic valve replacement (with emphasis on management of the small aortic root). J Thorac Cardiovasc Surg. 1978;75:300-8.

3. Rahimtoola S. The problem of valve prosthesis-patient mismatch. Circulation. 1978;58:20-4.

4. Pibarot P, Dumesnil J. Hemodynamic and clinical impact of prosthesis-patient mismatch in the aortic valve position and its prevention. J Am Coll Cardiol. 2000;36:1131-41.

5. Jin XY, Zhang ZM, Gibson DG, Yacoub MH, Pepper JR. Effects of valve substitute on changes in left ventricular function and hypertrophy after aortic valve replacement. Ann Thorac Surg. 1996;72:683-90.

6. Vitale N, Caldarera I, Muneretto C, Sinatra R, Scafuri A, Di Rosa E, et al. Clinical evaluation of St Jude Medical Hemodynamic Plus versus standard aortic valve prostheses: The Italian multicenter prospective randomized study. J Thorac Cardiovasc Surg. 2001;122: 691-8.

7. Yun KL, Sintek CF, Fletcher AD, Pfeffer TA, Kochamba GS, Hyde MR, et al. Aortic valve replacement with the Freestyle stentless bioprosthesis: five-year experience. Circulation. 1999;100(19 Suppl): II-17-23.

8. Westaby S, Huysmans HA, David TE. Stentless aortic bioprostheses: compelling data from the Second International Symposium. Ann Thorac Surg. 1998;65:235-40.

9. De Paulis R, Sommariva L, De Matteis GM, Caprara E, Tomai F, Penta de Peppo A, et al. Extent and pattern of regression of left ventricular hypertrophy in patients with small size CarboMedics aortic valves. J Thorac Cardiovasc Surg. 1997;113:901-9.

10. Rossi A, Tomaino M, Golia G, Anselmi M, Fuca G, Zardini P. Echocardiographic prediction of clinical outcome in medically treated patients with aortic stenosis. Am Heart J. 2000;140:766-71.

11. Dellgren G, Eriksson MJ, Blange I, Brodin LA, Radegran K, Sylven C. Angiotensin-converting enzyme gene polymorphism influences degree of left ventricular hypertrophy and its regression in patients undergoing operation for aortic stenosis. Am J Cardiol. 1999;84:90913. 